\title{
The effects of nurse-led health coaching on health-related quality of life and clinical health outcomes among frequent attenders: A quasi-experimental study
}

Kirsi Kivelä, Satu Elo, Helvi Kyngäs, Maria Kääriäinen, The effects of nurse-led health coaching on health-related quality of life and clinical health outcomes among frequent attenders: A quasiexperimental study, Patient Education and Counseling, Volume 103, Issue 8, 2020, Pages 15541561, ISSN 0738-3991, https://doi.org/10.1016/j.pec.2020.02.026

\begin{abstract}
Objective: To evaluate the effects of the nurse-led health coaching on health-related quality of life and clinical health outcomes among frequent attenders in primary healthcare.

Methods: A quasi-experimental study design. A total of 110 patients were enrolled in the study. The experimental group $(\mathrm{n}=52)$ received nurse-led health coaching and the control group $(\mathrm{n}=58)$ received the usual care at primary health care centres in Finland. The data were collected before the intervention and 12 months via a questionnaire of health-related quality of life and clinical health outcomes as measured by health-coaching nurses.

Results: This study found frequent attenders have low health-related quality of life. The nurse-led health coaching showed no differences in health-related quality of life between the experimental and control groups. However, the nurse-led health coaching had statistically significant effects on the blood pressure and health-related quality of life among the experimental participants, especially in emotional role limitation and energy.

Conclusions: This study suggests that nurse-led health coaching may lead to an improvement in the health-related quality of life and blood pressure among frequent attenders.

Practice Implications: The health-coaching sessions with own health-coaching nurses and action plans support the frequent attenders' health promotion goals and implementation.
\end{abstract}

Keywords: chronic diseases, coaching, health promotion, nurse, patient, primary health care, quality of life

\section{Introduction}

Chronic diseases represent a growing problem around the world [1]. Half of primary care patients have at least one chronic disease [2]. Moreover, chronic diseases decrease patients' quality of life and increase disability, morbidity, mortality and healthcare costs [1]. In European countries, chronic 
diseases make up 70-80\% of total healthcare expenditures [3]. Frequent visits to primary healthcare have been associated with illness, such as chronic diseases, physiological problems and mental disorders [4,5] although they also have social and economic difficulties [5]. These patients, who have high healthcare service use, suffer from multimorbidity $[4,6]$ and medically unexplained symptoms that usually cause new visits to primary healthcare [5]. They consume a large part of healthcare resources, resulting in costs to the national economy. In Finland, 10\% of the population produce 70$80 \%$ of the cost of social and healthcare services [7].

Several studies have found that frequent attenders experience poor health status [8-14] and a lower quality of life $[9,12,15,16]$. These studies found several predictive factors for frequent attendance, including older age, female gender, lower level of education, social and economic difficulties [17,18] and stressful life events [19-24]. However, the reviews [4,6] have found that frequent attenders are in all age groups. The quality of the physician-patient relationship has not been found to be associated with frequent attendance [25].

There is a need for interventions to assess the life management of frequent attenders with chronic diseases. An important determinant of the prevention and management of chronic diseases is healthrelated behaviour [26,27]. Having a healthy lifestyle helps to prevent many chronic diseases and improves overall quality of life [28]. Although public health efforts have been successful in increasing the knowledge and awareness of healthy guidelines and recommended practices, many patients have found them difficult to follow [27].

In an integrative review by Hale \& Giese [29] about the cost-effectiveness of health coaching, they found that health coaching has the potential to improve chronic-disease management and lower healthcare costs. In recent years, the number of health-coaching interventions has increased substantially. Health coaching is an individual patient-centred approach offered by healthcare professionals to provide empowerment and support for patients to help them determine their health related goals and to institute healthy behavioural changes [30,31]. The health coach uses motivational interviews, active listening and cognitive behavioural strategies to help patients become motivated and obtain skills to create sustainable change [31,32].

The effects of health coaching have been widely studied, especially in the arena of chronic diseases. Of the many possible types of interventions, health coaching has been found to be effective in chronic- 
disease management and for improving the health outcomes of patients with diabetes, hypertension, hyperlipidaemia, obesity, cardiovascular diseases, back pain and cancer [29,31,33-38]. According to the systematic review of Kivelä et al. [28], health coaching has positive effects on patients' physiological, behavioural and psychological conditions and on their social lives. Health coaching has been shown to be effective in changing chronic disease patients' lifestyle behaviours and improving their self-efficacy.

However, many interventions have been examined to assess the effects on patients with only one long-term disease [1,39]. Instead Panagioti et al. [39] evaluated telephone health coaching in older people with multimorbidity. These results showed that health coaching did not improve patient activation, quality of life, depression or self-care compared to usual care. On the other hand, health coaching via telephone was not effective in the long term [40-43]. However, some studies have shown that face-to-face interventions have proven to be more effective than the other interventions $[42,44]$.

Some studies have shown that higher usage of health services is associated with lower perceived health-related quality of life $[12,15,16,45]$. Health-related quality of life is a widely used multidimensional concept of an individual's subjective experience of physical, mental and social well-being and functioning [46,47]. It includes the effects of health, illness and treatment on an individual's quality of life [47]. It has also been noted that somatic diseases, older age, female gender, low educational level and a poor financial situation are associated with low health-related quality of life [48].

The results of the studies, the effects of health-coaching interventions on the health-related quality of life among people with chronic conditions, are varied. This is partly due to differences in interventions, such as target population and size, the method used and the length and duration of the interventions. However, health coaching has improved the health-related quality of life among the patients with chronic obstructive pulmonary diseases [49-51], cancer [36,52], type 2 diabetes, coronary artery disease and congestive heart failure [53].

To our knowledge, the effects of health coaching on the frequent attenders have not been studied in earlier research. There is also no clear evidence of interventions that have reinforced frequent attenders' health-related quality of life [54,55]. According to Malins et al. [56], cognitive behaviour therapy for long-term frequent attenders in primary care improved health-related quality of life at the 
six-month follow-up but this was not maintained at 12 months. The nurse-led case management model has not been shown to improve health-related quality of life among the frequent attenders during a two-year period [57].

The aim of this study was to evaluate the effects of nurse-led health coaching on the health-related quality of life and clinical health outcomes among frequent attenders in primary healthcare. We hypothesized that nurse-led health coaching (experimental group) has more positive effects on the health-related quality of life among frequent attenders compared to usual care (control group). In addition we hypothesized that experimental group has positive clinical health outcomes after nurseled health coaching.

\section{Methods}

\subsection{Study design}

A quasi-experimental nonrandomized study design with a control group was used with assessments done at baseline and at a 12-month follow-up.

\subsection{Study settings and participants}

This study was conducted from February 2015 to December 2016 at three primary healthcare centres in Oulu, Northern Finland, which has 200,000 inhabitants. A study population of 435 frequent attenders at three primary care centres in Oulu were invited to participate in the study. They were $3.2 \%$ of all the $\geq 18$ old years of age visitors to the three healthcare centres' physicians. This sample was collected retrospectively from the electronic medical records of primary healthcare centres for the year 2013.

Eligible patients were selected using the following inclusion criteria: 1) frequent attenders, who were defined as patients who had face-to-face visits to the physicians in the local primary healthcare centre at least seven times during a 12-month period, 2) aged 18 years or older, and 3) able to read and understand Finnish. The patients were excluded if they had visits due to pregnancy or delivery, serial treatment for the same disease, an inability to give informed consent or who were involved in another study intervention at the same time. 
In the study, all frequent attenders had the opportunity to participate in a health-coaching program in addition to the usual care. As shown in Figure 1, 143 patients gave written informed consent and were accepted into the study in October-November 2014. At baseline, a total of 110 semistructured postal questionnaires were returned to the researcher in February-December of 2015. The patient response rate was $77 \%$. The participants were divided into two groups, the experimental and control groups. The experimental group $(n=52)$ consisted of frequent attenders who had chosen the health-coaching program. The rest of the participants $(n=58)$ formed the control group. After 12 months, the followup results were returned to the researcher by post and included 34 frequent attenders of the experimental group and 30 frequent attenders of the control group.

\subsection{The intervention}

\subsubsection{Experimental group}

The experimental group consisted of 52 frequent attenders from all three health centres. The intervention was based on the customized nurse-led health-coaching program. The program consisted of an individual health-coaching nurse, health-coaching sessions and a written action plan according to each participant's individual needs.

First, all the experimental group's frequent attenders were assigned to their own nurse coach. The coaches were registered nurses with many years of experience in patient education in primary healthcare. Before this study, they took part in one-day training for the motivational interviewing techniques by a research and specialist. The nurses had used these techniques for three years. In addition, the nurse coaches received health-coaching training by a researcher familiar with health coaching. These educations were carried out in small groups, taking into account the nurses' previous skills.

Each participant's own health coaching nurse learned about the frequent attender's problems and individual needs through listening, motivational interviews and open-ended questions. On the basis of this information, the nurse coaches helped the frequent attenders to identify their life situations and define their goals for the plans. The goals and health coaching focused on the management and monitoring of chronic diseases, including medication adherence, self-care, lifestyle and behaviour 
changes, such as diet, exercise, weight management, smoking, alcohol consumption and stress management. The frequent attenders received their written plans for home self-care support. If they had numerous and/or difficult problems, the health-coaching nurses consulted the physicians and organized a multidisciplinary support team for the frequent attenders. In the follow-up sessions, the nurse coaches assessed the frequent attenders' stage of changes, motivated them toward lifestyle and behavioural changes, gave emotional support, provided information and feedback and helped the frequent attenders to remain committed to achieving the goals that had been set.

The intervention's duration was 12 months. The participants received at least two personal face-toface sessions: at commencement and after 12 months. In addition, the program included follow-up sessions that were implemented either via telephone, face-to-face or in combination. Although sessions were not limited, the average number of face-to-face sessions was three and telephone was two. All face-to-face sessions lasted 30-60 minutes and telephone sessions 15-30 minutes.

The experimental group $(\mathrm{n}=52)$ participated in measurements at the baseline study. After 12 months, the health-coaching program had 46 participants. The follow-up measurements resulted in 30 participants.

\subsubsection{The control group}

The control group consisted of 58 frequent attenders. They, along with the experimental group, received the usual care regarding their health problems from the physicians and nurses at the primary healthcare centres if they needed it. The usual care for frequent attenders included assessment for the need of treatment, physical examination, problem assessment, laboratory and X-ray tests, medical advice and patient support and education during their visits. 30 frequent attenders of the control group participated in the follow-up measurements of the health-related quality of life after 12 months.

\subsection{Data collection}

Data were collected via a postal questionnaire during 2015-2016. The questionnaire included sociodemographic variables and health-related quality of life. Sociodemographic variables included sex, age, civil status, occupational status, educational level and chronic disease. Chronic diseases 
were classified into diagnostic groups using the International Statistical Classification of Diseases and Related Health Problems $10^{\text {th }}$ Revision (ICD-10) [58].

The primary outcome was health-related quality of life. It was measured using the validated Finnish version of the RAND 36-Item Health Survey 1.0 (RAND-36) [45]. The 36-item self-report instrument consists of eight separate scales of quality of life: (1) physical functioning (10 items), (2) physical role functioning (four items), (3) emotional role functioning (three items), (4) social role functioning (two items), (5) bodily pain (two items), (6) mental health (five items), (7) energy (four items) and (8) general health (five items). The RAND-36 includes exactly the same questions as the Medical Outcomes Study 36-item short-form health survey (MOS SF-36), but the scoring of the general health and bodily pain scales differs slightly [59]. The scores were calculated in a two-step process using the instructions provided by Ware et al. in the user's manual [60]. First, all items were scored on a scale from 0 to 100. A higher score defines a better health or function. Second, items in the same scale were averaged together to create the eight scale scores. Scale scores represented the average for all items in the scale. In a Finnish study, which were conducted on randomly selected general population from the age group 18 - 79, was used the RAND-36. The Cronbach's alpha values for all eight scales varied between 0.80 and 0.94 [45]. Similarly, in this study, the Cronbach's alpha coefficients for each scale were between 0.77 and 0.93 .

Secondary outcomes for the experimental group were clinical health outcomes: weight (kg), body mass index (BMI) $\left(\mathrm{kg} / \mathrm{m}^{2}\right)$, systolic and diastolic blood pressure $(\mathrm{mmHg})$. Health-coaching nurses measured all these clinical health outcomes in the face-to-face sessions at the primary health care in the beginning and after 12 months.

\subsection{Data analysis}

The data was analysed using IBM SPSS $25.0 ®$ for Windows. The characteristics of frequent attenders were examined using descriptive statistics (frequencies, percentages, mean, range and SD (standard deviation)). The missing data were replaced using the means. Normal distribution of the data was assessed via histograms by the Shapiro-Wilk Test. The Mann-Whitney's U Test was used for comparison between the groups with a skewed distribution. Normally distributed were analysed with the Independent Samples Test. 
The Wilcoxon Signed Ranks Test was used to compare the different mean scores on the baseline and 12-month follow-up measurements in the experimental and control groups if they were a skewed distribution. The Paired Samples T Test used for those with a normally distributed. The statistical tests were two-tailed, and the significance level was set at $\rho<0.05$.

\subsection{Ethical considerations}

Ethical approval was obtained from the Ethical Committee of Northern Ostrobothnia Hospital District, and permission to conduct the study was obtained from the city of Oulu. The frequent attenders received the cover letter, in which they were informed about this study and that participation in the study was voluntary, free of cost and could be interrupted at any point. All participants gave written informed consent before the baseline measurements. The study was conducted following good ethical practice [61].

\section{Results}

\subsection{Sociodemographic characteristics}

Two-thirds of the respondents were women. The mean age was 66 years (SD 14.7), and the majority of the frequent attenders $(83 \%)$ were retired. More than half of the respondents $(57 \%)$ were married or lived with someone. Half of the respondents (50\%) had completed a secondary level education. Ninety-eight percent of the frequent attenders suffered from chronic diseases. They had an average of 3.8 chronic diseases. The most commonly reported chronic diseases recognized by the ICD-10 were diseases of the musculoskeletal system and connective tissue and diseases of the circulatory system. There were no statistical differences in the sociodemographic and chronic diseases' characteristics of the frequent attenders between the experimental and control groups. The background information of the frequent attenders is shown in Table 1.

\subsection{Health-related quality of life}

In this study were evaluated the effects of the nurse-led health coaching on health-related quality of life and clinical health outcomes among frequent attenders in primary healthcare. The effects of nurseled health coaching on health-related quality of life measured from eight scales found that emotional 
role limitation $(\rho=0.009)$ and energy $(\rho=0.017)$ were statistically significant from the baseline to measurement after 12 months in the experimental group (Figure 2). In addition, the mean values of physical role limitations (mean change +6.6 ), emotional well-being (mean change +5.1 ), bodily pain (mean change +2.1) and general health (mean change +1.0 ) increased even if there were no statistically significant differences observed (Table 2).

In the control group, health-related quality of life measured from eight scales found that only bodily pain $(\rho=0.020)$ had a statistically significant change from the baseline to measurement after 12 months (Figure 2). In addition to this, the mean values of physical role limitations (mean change +6.9 ), energy (mean change +1.3 ) and physical functioning (mean change +0.3 ) also improved during the 12 months even if no statistically significant differences were found (Table 2).

There were no statistically significant differences between the experimental and control groups during the baseline measurements and after the 12 months (Table 2).

\subsection{Clinical health outcomes}

The effects of the nurse-led health coaching were evaluated on the clinical health outcomes in the experimental group. Mean changes of the clinical health outcomes in the experimental group from baseline to 12 months for weight, BMI, systolic and diastolic blood pressures are shown in figure 3 . Diastolic blood pressure (mean change $-3.8 \mathrm{mmHg}, \rho=0.034$ ) had a statistically significant change. Moreover, we observed a decrease in systolic blood pressure (mean change $-4.3 \mathrm{mmHg}, \rho=0.059$ ). There were no major changes in the weight and BMI. The experimental group ranged in BMI was $16-40 \mathrm{~kg} / \mathrm{m}^{2}$.

\section{Discussion and Conclusion}

\subsection{Discussion}

The present study describes the effects of a health-coaching intervention on health-related quality of life and clinical health outcomes among frequent attenders in primary healthcare centres in Finland. We compared nonrandomized to the experimental and control groups during 12 months follow-up in 2015-2016. To the best of our knowledge, we are the first to design and test health coaching for 
frequent attenders. As the frequent attenders visit a large number of primary healthcare providers, it is important to evaluate the effects of the different patient-education approaches for these patients.

The findings of this study showed that the health coaching had positive effects on the health-related quality of life. Six out of eight different scales improved by mean changes. Additionally, emotional role limitation and energy changes had statistically significant differences from baseline to 12 months. These results support frequent attenders have stressful life events and experiences [19-23] that can be influenced by health coaching. The nurse listening, motivating and supporting the patients can help determine and achieve health related goals in small steps and lead to behavioural changes. Setting the new goals can lead to better well-being. This positive result corresponds to previous studies, in which health-coaching interventions improved health-related quality of life among patients with chronic diseases [36,50,52,53]. However, this study did not measure the experiences of the experimental group or the nurse coaches in the health coaching process. In the future, research should also evaluate the success of the intervention.

In a systematic review by Oliveira et al. [62], health coaching was effective for increasing physical activity among older people. In this study, the results of physical activity were reversed. Additionally, in the experimental group, social functioning changed for the worse. In the control group with usual care, bodily pain improved significantly during the 12 months.

At the baseline, health-related quality of life did not differ statistically significantly between the experimental and control groups. Between the groups, the biggest mean change was found to be emotional role limitations. The health coaching was not found to have made statistically significant differences between the experimental and control groups during the 12 months. This may partly due to the low participation rate $(33 \%)$. All participants were given the opportunity to participate in the health-coaching program, but less than half of the participants wanted to participate. For this reason, this study was not randomized. We also calculated power and sample size to evaluate the correct sample size for this study [63]. Therefore, all frequent attenders $(n=435)$ were invited to the study.

The present study was measured weight, BMI and blood pressure from the experimental group. The findings showed that the nurse-led health coaching has positive impact on blood pressure. Diastolic blood pressure improved statistically significant during 12 months even thought their means were in line with the medical recommendations at the beginning measurements. Hersey's [68] study results 
of blood pressure supported our study. However, there are also the studies, where health coaching has not been shown to have any effect on blood pressure [43,64-67]. Variability in results between the studies may be due to normal daily variability in blood pressure and to the time and conditions of measurements. In contrast, there was no positive change in body weight and BMI. In the previous studies, health coaching has been shown to have an effect on decreasing weight or BMI $[42,44,65,66,68]$. It may be that frequent attenders see weight loss as too much of a challenge because of their reduced health-related quality of life.

The experimental and control groups were fairly homogeneous according to background information. Sociodemographic factors, older age (mean 66 years), female gender (67\%) and several chronic diseases (mean 3.8) demonstrated that the sample of frequent attenders had general characteristics of frequent attenders. In the earlier studies, older age, a low level of education, morbidity and poor financial situation were related to a lower health-related quality of life [5,17,24]. Moreover, high usage of healthcare services has clearly been linked to a low health-related quality of life $[12,15,16]$. For these reasons, the health-related quality of life between the groups may not have been affected as expected.

In the Finnish study by Aalto et al. [45], all eight scales of health-related quality of life (RAND-36) among the general population were clearly better than the frequent attenders of this study. However, all the scales of the health-related quality of life of frequent attenders were in the same direction as the Finnish population with three or more chronic diseases. Aalto et al. [45] found more chronic diseases mean a worse health-related quality of life. In addition, among healthy and chronic diseases patients, it was noted that high health-service users felt worse about their well-being.

Although our study's target group was frequent attenders, we did not study the impact of health coaching on health service usage because it would probably increase with the intervention [54]. The duration of the intervention was defined as 12 months because significant multiple behavioural changes took at least six months $[69,70]$. The number of sessions were individual, depending on the need of the frequent attender. The number of face-to-face sessions ranged from two to six and telephone sessions from zero to five. No regular sessions were set because frequent attenders had their own health-coaching nurse. 
The healthcare professionals had important roles. In this study, the health-coaching nurses accomplished the sessions of intervention along with their normal work in primary healthcare. We believe that the health-coaching nurses performed well since almost all participants of the experimental group continued on to the end of the study; only five participants dropped out. The nurses' coaching skills were not tested in advance. This could have affected the results of the intervention.

\section{Strengths and limitations of the study}

A major strength of quasi-experimental study was that this was possible to conduct in clinical settings. The outcome data were collected before and after implementing the intervention. In addition, reliability was confirmed using by the control group [71].

The data were collected using a known instrument (the RAND-36) [60]. The Finnish version of the RAND-36 has also been demonstrated to have good reliability and construct validity [45]. In this study, the RAND-36 had high internal validity. Cronbach's alphas values for all eight scales were 0.77-0.93. Even if the instrument was self-reported, there were very few missing values in the completed questionnaires returned by the participants.

The weight, BMI and blood pressure measurements from the experimental group were performed by the health-coaching nurses at the primary healthcare. The results of these clinical health outcomes are more reliable measured by the health care professional than by the participant himself. The control group were not measured the clinical health outcomes because they did not have scheduled visits to primary healthcare.

The sample of this study was small because only $33 \%$ of the population gave written informed consent. In the beginning of this study, it was already known that frequent attenders were at risk for a target group. Frequent attenders in primary healthcare had many chronic diseases and were elderly (mean 66 years). They might not have the resources to participate in the study due to their impaired health status. However, the response rate was quite good $(76.9 \%)$ at the baseline measurement and satisfactory at 12 months follow-up measurement with the experimental group $65.4 \%$ and the control group $51.7 \%$. 
In this study, the data collection and processing of the results were carefully carried out. The generalization of the results is limited because the study was performed in one city in Northern Finland and the participants have not been randomized to groups.

\subsection{Conclusions}

This study showed that the frequent attenders have a lower health-related quality of life. However, the nurse-led health coaching had positive effects on the blood pressure and health-related quality of life among frequent attenders, especially in emotional role limitation and energy during the 12 months. Moreover, the experimental group's physical role limitations, emotional well-being and general health improved slightly. However, there were no differences between the experimental and control groups.

\subsection{Practice implications}

The health-coaching method supports the frequent attenders' participation in their care and thus produces health effects. The action plans, health-coaching sessions with own health-coaching nurses support the frequent attenders' health promotion goals and implementation. Health-coaching nurses are critically positioned to motivate frequent attenders' ${ }^{\prime}$ willingness to change their lifestyles, and the nurses help and support the patients to achieve their goals.

This study suggests that in the future, health coaching can be used in primary healthcare for frequent attenders and other patients with chronic diseases. It is an easy method to learn and use and does not incur extra healthcare costs. However, further research is needed to examine the effectiveness and cost-effectiveness of random controlled trial health-coaching interventions for frequent attenders who consume the most primary healthcare services.

\section{Conflicts of interest statement}

No conflicts of interest have been declared by the authors. The authors alone are responsible for the content and the writing of the paper. 


\section{Acknowledgements}

The city of Oulu gave financial support to this study. The authors also thank the staff of the health centres in the city of Oulu for data collection.

\section{References}

[1] K.R. Boehmer, S. Barakat, S. Ahn, L.J. Prokop, P.J. Erwin, M.H. Murad, Health coaching interventions for persons with chronic conditions: a systematic review and meta-analysis protocol, Syst. Rev. 5 (2016) 146.

[2] B.W. Ward, J.S. Schiller, R.A. Goodman, Multiple chronic conditions among US adults: a 2012 update, Prev. Chronic Dis. 11 (2014) E62.

[3] M. Rijken, V. Struckmann, M. Dyakova, M.G. Melchiorre, S. Rissanen, E. van Ginneken, on the behalf of the ICARE-EU partners, ICARE 4EU: Improving care for people with multiple chronic conditions in Europe, Eurohealth 19 (2013) 29-31.

[4] P. Vedsted, M.B. Christensen, Frequent attenders in general practice care: a literature review with special reference to methodological considerations, Public Health 119 (2005) 118-137.

[5] K. Kivelä, S. Elo, M. Kääriäinen, Frequent attenders in primary health care: a concept analysis, Int. J. Nurs. Stud. 86 (2018) 115-124.

[6] D. Gill, M. Sharpe, Frequent consulters in general practice: a systematic review of studies of prevalence, associations and outcome, J. Psychosom. Res. 47 (1999) 115-130.

[7] R-L. Leskelä, V. Komssi, S. Sandström, S. Pikkujämsä, A. Haverinen, S-L. Olli, K. YlitaloKatajisto, Heavy users of social and health care services in the city of Oulu (in Finnish), Suom. Laakaril. 68 (2013) 3163-3169.

[8] P. Vedsted, F. Olesen, Social environment and frequent attendance in Danish general practice, Br. J. Gen. Pract. 55 (2005) 510-515.

[9] B. van Steenkiste, M.F. Knevel, M. van den Akker, J.F. Metsemakers, Increased attendance rate: BMI matters, lifestyles don't. Results from the Dutch SMILE study. Fam. Pract. 27 (2010) 632637.

[10] J. Norton, M. David, G. de Roquefeuil, J. Boulenger, J. Car, K. Ritchie, A. Mann, Frequent attendance in family practice and common mental disorders in an open access health care system, $\mathrm{J}$. Psychosom. Res. 72 (2012) 413-418.

[11] R.E. Taylor, T. Marshall, A. Mann, D.P. Goldberg, Insecure attachment and frequent attendance in primary care: a longitudinal cohort study of medically unexplained symptom presentations in ten UK general practices, Psychol. Med. 42 (2012) 855-864. 
[12] J. Rifel, I. Švab, P. Selič, D.R. Pavlič, I. Nazareth, J. Car, Association of common mental disorders and quality of life with the frequency of attendance in Slovenian family medicine practices: longitudinal study, PLoS One 8 (2013) e54241.

[13] A. Kaattari, H. Tiirinki, L. Turkki, T. Nordström, A. Taanila, Characteristics of frequent users of primary health care, J. Soc. Med. 52 (2015) 191-201.

[14] C. Pymont, P. Butterworth, Changing circumstances drive changing attendance: a longitudinal cohort study of time varying predictors of frequent attendance in primary health care, J. Psychosom. Res. 79 (2015) 498-505.

[15] J. Kersnik, I. Scvab, M. Vegnuti, Frequent attenders in general practice: quality of life, patient satisfaction, use of medical services and GP characteristics, Scand. J. Prim. Health Care 19 (2001) 174-177.

[16] S. Patel, J. Kai, C. Atha, A. Avery, B. Guo, M. James, S. Malins, C. Sampson, M. Stubley, R. Morriss, Clinical characteristics of persistent frequent attenders in primary care: case-control study, Fam. Pract. 32 (2015) 624-630.

[17] J.T. Jørgensen, J.S. Andersen, A. Tjønneland, Z.J. Andersen, Determinants of frequent attendance in Danish general practice: a cohort-based cross-sectional study, BMC Fam. Pract. 17 (2016) 9.

[18] A.A. Pasgaard, M.H. Maehlisen, C. Overgaard, L. Ejlskov, C. Torp-Pedersen, H. Bøggild, Social capital and frequent attenders in general practice: a register-based cohort study, BMC Public Health 18 (2018) 310.

[19] A. Matalon, T. Nachmani, S. Rabin, B. Maoz, The narrative approach as an effective single intervention in functional somatic symptoms in a multi-disciplinary referral clinic for primary care frequent attenders, Fam. Pract. 22 (2004) 114-117.

[20] J. Glaser, J. van Os, P.J. Portegijs, I. Myin-Germeys, Childhood trauma and emotional reactivity to daily life stress in adult frequent attenders of general practitioners, J. Psychosom. Res. 61 (2006) 229-236.

[21] H. Bergh, A. Baigi, J. Månsson, B. Mattsson, B. Marklund, Predictive factors for long-term sick leave and disability pension among frequent and normal attenders in primary health care over 5 years, Public Health 121 (2007) 25-33.

[22] F.T. Smits, H.J. Brouwer, A.H. Zwinderman, J. Mohrs, A.H. Schene, H.C. van Weert, G. ter Riet, Why do they keep coming back? Psychosocial etiology of persistence of frequent attendance in primary care: a prospective cohort study, J. Psychosom. Res. 77 (2014) 492-503. 
[23] C. Pymont, P. Butterworth, Longitudinal cohort study describing persistent frequent attenders in Australian primary healthcare, BMJ Open 5 (2015) e008975.

[24] A. Hajek, J-O. Bock, H-H. König, Association of general psychological factors with frequent attendance in primary care: a population-based cross-sectional observational study, BMC Fam. Pract. 18 (2017) 48.

[25] A. Dinkel, A. Schneider, G. Schmutzer, E. Brähler, W. Häuser, Family physician-patient relationship and frequent attendance of primary and specialist health care: results from a German population-based cohort study, Patient Educ. Couns. 99 (2016) 1213-1219.

[26] S. Yusuf, S. Hawken, S. Ounpuu, T. Dans, A. Avezum, F. Lanas, M. McQueen, A. Budaj, P. Pais, J. Varigos, L. Lisheng, Effect of potentially modifiable risk factors associated with myocardional infarction in 52 countries (the INTERHEAT study): case-control study, Lancet 364 (2004) 937-952.

[27] A. Linden, S.W. Butterworth, J.O. Prochasca, Motivational interviewing-based health coaching as a chronic care intervention, J. Eval. Clin. Pract. 16 (2010) 166-174.

[28] K. Kivelä, S. Elo, H. Kyngäs, M. Kääriäinen, The effects of health coaching on adult patients with chronic diseases: a systematic review, Patient Educ. Couns. 97 (2014) 147-157.

[29] R. Hale, J. Giese, Cost-effectiveness of health coaching: an integrative review, Prof. Case Manag. 22 (2017) 228-238.

[30] K.L. Lawson, Y. Jonk, H. O’Connor, K.S. Riise, D.M. Eisenberg, M.J. Kreitzer, The impact of telephonic health coaching on health outcomes in a high-risk population, Glob. Adv. Health Med. 2 (2013) 40-47.

[31] R.Q. Wolever, L.A. Simmons, G.A., Sforzo, D. Dill, M. Kaye, E.M., Bechard, M.E. Southard, M. Kennedy, J. Vosloo, N. Yang, A systematic review of the literature on health and wellness coaching: defining a key behavioral intervention in healthcare, Glob. Adv. Health Med. 2 (2013) 38-57.

[32] E. Hayes, K.A. Kalmakis, From the sidelines: coaching as a nurse practitioner strategy for improving health outcomes, J. Am. Acad. Nurse Pract. 19 (2007) 555- 62.

[33] M.J. Vale, M.V. Jelinek, J.D. Best, A.M. Dart, L.E. Grigg, D.L. Hare, D.L. Ho, R.W. Newman, J.J. McNeil, Coaching patients on achieving cardiovascular health (COACH): a multicenter randomized trial in patients with coronary heart disease, Arch. Intern. Med. 163 (2003) 2775-2783. 
[34] R.Q. Wolever, M. Dreusicke, J. Fikkan, T.V. Hawkins, S. Yeung, J. Wakefield, L. Duda, P. Flowers, C. Cook, E. Skinner, Integrative health coaching for patients with type 2 diabetes: a randomized clinical trial, Diabetes Educ. 36 (2010) 629-39.

[35] R. Iles, N.F. Taylor, M. Davidson, P. O’Halloran, Telephone coaching can increase activity levels for people with non-chronic low back pain: a randomised trial, J. Physiother 57 (2011) 231238.

[36] M.L. Thomas, J.E. Elliott, S.M. Rao, K.F. Fahey, S.M. Paul, C. Miaskowski, A randomized, clinical trial of education or motivational-interviewing-based coaching compared to usual care to improve cancer pain management, Oncol. Nurs. Forum 39 (2012) 39-49.

[37] C. Liddy, S. Johnston, K. Nash, N. Ward, H. Irving, Health coaching in primary care: a feasibility model for diabetes care, BMC Fam. Pract. 15 (2014) 60.

[38] N. Wayne, D.F. Perez, D.M. Kaplan, P. Ritvo, Health coaching reduces HbA1c in type 2 diabetic patients from a lower-socioeconomic status community: a randomized controlled trial, J. Med. Internet Res. 17 (2015) e224.

[39] M. Panagioti, D. Reeves, R. Meacock, B. Parkinson, K. Lovell, M. Hann, K. Howells, A. Blakemore, L. Rist, P. Coventry, T. Blakeman, M. Sidaway, P. Bower, Is telephone health coaching a useful population health strategy for supporting older people with multimorbidity? An evaluation of reach, effectiveness and cost-effectiveness using a 'trial within a cohort', BMC Medicine. 16 (2018) 80.

[40] L.A.L. Dejonghe, J. Becker, I. Froboese, A. Schaller, Long-term effectiveness of health coaching in rehabilitation and prevention: a systematic review, Patient Educ. Couns. 100 (2017) 1643-1653.

[41] K.M. Emmons, E. Puleo, M.L. Greaney, M.W. Gillman, C.G. Bennett, J. Haines, K. SprunckHarrild, K. Viswanath, A randomized comparative effectiveness study of Healthy Directions 2-a multiple risk behavior intervention for primary care, Prev. Med. 64 (2014) 96-102.

[42] E.S. Pearson, J.D. Irwin, D. Morrow, D.S. Battram, J.C.W. Melling, The CHANGE program: comparing an interactive vs. prescriptive approach to self-management among university students with obesity, Can J. Diabetes 37 (2013) 4-11.

[43] K. Patja, P. Absetz, A. Auvinen, K. Tokola, J. Kytö, E. Oksman, R. Kuronen, T. Ovaska, K. Harno, M. Nenonen, T. Wiklund, R. Kettunen, M. Talja, Health coaching by telephony to support self-care in chronic diseases: clinical outcomes from the TERVA randomized controlled trial, BMC Health Serv Res 12 (2012) 147-154. 
[44] J. Ma, V. Yank, L. Xiao, P.W. Lavori, L.G. Wilson, R.S. Stafford, Translating the Diabetes Prevention Program lifestyle intervention for weight loss into primary care: a randomized trial, JAMA Intern. Med. 173 (2013) 113-121.

[45] A-M. Aalto, A.R. Aro, J. Teperi, RAND-36 as a measure of Health-Related Quality of Life. Reliability, construct validity and reference values in the Finnish general population (in Finnish, English summary). National Research and Development Center for Welfare and Health, Research Reports 101, Stakes, Helsinki, 1999.

[46] R.D. Hays, L.S. Morales, The RAND-36 measure of health-related quality of life, Ann. Med. 33 (2001) 350-357.

[47] C.E. Ferrans, J.J Zerwic, J.E. Wilbur, J.L. Larson, Conceptual model of health-related quality of life, J. Nurs. Scholarsh. 37 (2005) 336-342.

[48] S.I. Saarni, T. Härkänen, H. Sintonen, J. Suvisaari, S. Koskinen, A. Aromaa, J. Lönnqvist, The impact of 29 chronic conditions on health-related quality of life: a general population survey in Finland using 15D and EQ-5D, Qual. Life Res. 15 (2006) 1403-1414.

[49] R. Benzo, K. Vickers, P.J. Novotny, S. Tucker, J. Hoult, P. Neuenfeldt, J. Connett, K. Lorig, C. McEvoy, Health Coaching and Chronic Obstructive Pulmonary Disease Rehospitalization, Am. J. Respir. Crit. Care Med. 194 (2016) 672-680.

[50] H. Rehman, K. Craig, K.V. Douglas, R.P. Benzo, Effect of a motivational interviewing-based health coaching on quality of life in subjects with COPD, Respir. Care 62 (2017) 1043-1048.

[51] D. Tülüce, S. Kutlutürkan, The effect of health coaching on treatment adherence, self-efficacy, and quality of life in patients with chronic obstructive pulmonary disease, Int. J. Nurs. Pract. 24 (2018) E12661.

[52] A.L. Hawkes, T.A. Patrao, A. Green, J.F. Aitken, CanPrevent: a telephone-delivered intervention to reduce multiple behavioural risk factors for colorectal cancer, BMC Cancer 27 (2012) 560 .

[53] E. Oksman, M. Linna, I. Hörhammer, J. Lammintakanen, M. Talja, Cost-effectiveness analysis for a tele-based health coaching program for chronic disease in primary care, BMC Health Serv. Res. 17 (2017) 138.

[54] F.T. Smits, J.J. Mohrs, E.E. Beem, P.J. Bindels, H.C. van Weert, Defining frequent attendance in general practice, BMC Fam. Pract. 9 (2008) 21.

[55] D. Haroun, F. Smits, F. van Etten-Jamaludin, A. Schene, H. van Weert, G. ter Riet, The effects of interventions on quality of life, morbidity and consultation frequency in frequent attenders in primary care: a systematic review, Eur. J. Gen. Pract. 22 (2) (2016) 71-82. 
[56] S. Malins, J. Kai, C. Atha, A. Avery, B. Guo, M. James, S. Patel, C. Sampson, M. Stubley, R. Morriss, Cognitive behaviour therapy for long-term frequent attenders in primary care: a feasibility case series and treatment development study, Br. J. Gen. Pract. 66 (2016) e729-736.

[57] S. Hirsikangas, O. Kanste, J. Korpelainen, R. Bloigu, H. Kyngäs, The effects of intervention on the quality of life, sense of coherence and daily activities of frequent attenders, J. Nurs. Educ. Pract. 8 (2018) 63-71.

[58] World Health Organization, ISD-10 International Statistical Classification of Diseases and Related Health Problems, tenth rev, WHO, Geneva, 2008.

[59] R.D. Hays, C.D. Sherbourne, R.M. Mazel, The RAND 36-item Health Survey 1.0, Health Econ. 2 (1993) 217-227.

[60] J.E. Ware, M. Kosinski, S.D. Keller, SF-36 Physical and mental health summary scales: a user's manual, fifth ed, The Health Institute, Boston, MA, 1994.

[61] Finnish Advisory Board on Research Integrity, Responsible conduct of research and procedures for handling allegations of misconduct in Finland, TENK, Helsinki, 2012.

[62] J.S. Oliveira, C. Sherrington, A.B. Amorim, A.B. Dario, A. Tiedemann, What is the effect of health coaching on physical activity in people aged 60 years and over? A systematic review of randomized controlled trials, Br. J. Sports Med. 51 (2017) 1425-1432.

[63] B.H. Munro, Statistical Methods for Health Care Research, fifth ed, Lippincott Williams \& Wilkins, Philadelphia, 2005.

[64] R. Navicharern, Y. Aungsuroch, S. Thanasilp, Effects of multifaceted nursecoaching intervention on diabetic complications and satisfaction of persons with type 2 diabetes, $\mathrm{J}$ Med Assoc Thai 92 (2009) 1102-1112.

[65] J.H. Rimmer, A. Rauworth, E. Wang, P.S. Heckerling, B.S. Gerber, A randomized controlled trial to increase physical activity and reduce obesity in a predominantly African American group of women with mobility disabilities and severe obesity, Prev Med 48 (2009) 473-479.

[66] G.G. Bennett, S.J. Herring, E. Puleo, E.K. Stein, K.M. Emmons, M.W. Gillman, Webbased weight loss in primary care: a randomized controlled trial, Obesity (Silver Spring) 18 (2010) 308313.

[67] F.J. Selvaraj, M. Mohamed, K. Omar, S. Nanthan, Z. Kusiar, S.Y. Subramaniam, N. Ali, K. Karanakaran, F. Ahmad, W.H. Low, DISSEMINATE Study Group, The impact of a disease management program $(\mathrm{COACH})$ on the attainment of better cardiovascular risk control in dyslipidaemic patients at primary care centres (The DISSAMINATE Study): a randomised controlled trial, BMC Fam Pract 13 (2012) 97. 
[68] J.C. Hersey, O. Khavjou, L.B. Strange, R.L. Atkinson, S.N. Blair, S. Campbell, C.L. Hobbs, B. Kelly, T.M. Fitzgerald, J. Kish-Doto, M.A. Koch, B. Munoz, E. Peele, J. Stockdale, C. Augustine, G. Mitchell, D. Arday, J. Kugker, P. Dorn, J. Ellzy, R. Julian, J. Grissom, M. Britt, The efficacy and cost-effectiveness of a community weight management intervention: a randomized controlled trial of the health weight management demonstration, Prev Med 54 (2012) 42-49.

[69] J.O. Prochaska, S. Butterworth, C.A. Redding, V. Burden, N. Perrin, M. Leo, M. FlahertyRobb, J.M. Prochaska, Initial efficacy of MI, TTM tailoring and HRI's with multiple behaviors for employee health promotion, Prev. Med. 46 (2008) 226-31.

[70] J.M. Olsen, B.J. Nesbitt, Health coaching to improve healthy lifestyle behaviors: an integrative review, Am. J. Health Promot. 25 (2010) e1-e12.

[71] D.F. Polit, C.T. Beck, Nursing Research: Generating and Assessing Evidence for Nursing Practice, 9th Edition, Lippincott, Williams \& Wilkins, Philadelphia, 2012.

\section{Legends}

Table 1. Background information of the frequent attenders $(n=110)$.

Table 2. Health-related quality of life for eight scales of measurements changes (post-pre).

Figure 1. Flow diagram of participants through health-coaching study.

Figure 2. Health-related quality of life for eight scales of measurements at baseline (pre) and after 12 months (post).

Figure 3. Clinical health outcomes of the experimental group $(n=34)$. 
Table 1. Background information of the frequent attenders $(n=110)$.

\begin{tabular}{|c|c|c|}
\hline Characteristics & $f$ & $\%$ \\
\hline \multicolumn{3}{|l|}{ Sex } \\
\hline Female & 74 & 67 \\
\hline Male & 36 & 33 \\
\hline \multicolumn{3}{|l|}{ Age (years)* } \\
\hline $18-39$ & 7 & 6 \\
\hline $40-64$ & 30 & 27 \\
\hline$\geq 65$ & 73 & 67 \\
\hline \multicolumn{3}{|l|}{ Marital status } \\
\hline Married or live together & 63 & 57 \\
\hline Unmarried & 13 & 12 \\
\hline Separated/divorced & 17 & 16 \\
\hline Widowed & 16 & 15 \\
\hline \multicolumn{3}{|l|}{ Occupational status } \\
\hline Employed & 8 & 7 \\
\hline Unemployed & 5 & 5 \\
\hline Retired & 91 & 83 \\
\hline Other & 5 & 5 \\
\hline \multicolumn{3}{|l|}{ Education } \\
\hline Primary & 35 & 32 \\
\hline Intermediate & 6 & 5 \\
\hline Secondary & 55 & 50 \\
\hline High & 14 & 13 \\
\hline \multicolumn{3}{|l|}{ Number of chronic diseases $* *$} \\
\hline 0 & 2 & 2 \\
\hline 1 or 2 & 36 & 35 \\
\hline 3 or 4 & 35 & 35 \\
\hline$\geq 5$ & 28 & 28 \\
\hline \multicolumn{3}{|l|}{ Most common chronic diseases of FAs by ICD-10 } \\
\hline Diseases of the musculoskeletal system and connective tissue & 96 & 95 \\
\hline Diseases of the circulatory system & 94 & 93 \\
\hline Diseases of the respiratory system & 45 & 45 \\
\hline Endocrine, nutritional and metabolic diseases & 41 & 41 \\
\hline Diseases of the digestive system & 23 & 23 \\
\hline Mental and behavioural disorders & 17 & 17 \\
\hline Diseases of the nervous system & 15 & 15 \\
\hline
\end{tabular}

* Mean age 66 years (SD 14.7, range 20-90 years)

** Number of chronic diseases mean 3.8 (SD 2.8, range 0-17) 
Table 2. Health-related quality of life for eight scales of measurements changes (post-pre).

\begin{tabular}{|c|c|c|c|c|c|c|}
\hline \multirow[b]{2}{*}{ Measure } & \multicolumn{2}{|c|}{$\begin{array}{l}\text { The experimental } \\
\text { group }(n=34)\end{array}$} & \multicolumn{2}{|c|}{$\begin{array}{l}\text { The control group (n } \\
=30)\end{array}$} & \multicolumn{2}{|c|}{$\begin{array}{l}\text { The experimental } \\
\text { and control } \\
\text { groups }\end{array}$} \\
\hline & $\begin{array}{l}\text { Post-pre } \\
\text { mean } \\
\text { change, (SD) }\end{array}$ & $\begin{array}{l}\rho \\
\text { value* }^{*}\end{array}$ & $\begin{array}{l}\text { Post-pre } \\
\text { mean } \\
\text { change, } \\
\text { (SD) }\end{array}$ & $\rho$ value* & $\begin{array}{l}\text { Pre } \\
\rho \\
\text { value }^{\wedge}\end{array}$ & $\begin{array}{l}\text { Post } \\
\rho \\
\text { value }^{\wedge}\end{array}$ \\
\hline Physical functioning & $-1,8(12.8)$ & $0.617 * *$ & $0.3(14.7)$ & $0.969 * *$ & $0.881^{\wedge \wedge}$ & $0.653^{\wedge \wedge}$ \\
\hline Physical role limitation: & $6.6(29.7)$ & 0.245 & $6.9(34.2)$ & 0.357 & 0.662 & 0.787 \\
\hline $\begin{array}{l}\text { Emotional role } \\
\text { limitations }\end{array}$ & $20.6(42.7)$ & 0.009 & $-5.6(42.1)$ & 0.548 & 0.184 & 0.088 \\
\hline Energy & $7.4(17.0)$ & 0.017 & $1.3(18.3)$ & 0.241 & 0.128 & 0.903 \\
\hline Emotional well-being & $5.1(16.0)$ & $0.051 * *$ & $-3.4(13.3)$ & $0.475 * *$ & $0.087^{\wedge \wedge}$ & $0.883^{\wedge \wedge}$ \\
\hline Social functioning & $-1.8(27.0)$ & 0.808 & $-2.1(32.5)$ & 0.717 & 0.347 & 0.658 \\
\hline Bodily pain & $2.1(26.1)$ & $0.987 * *$ & $9.6(20.5)$ & $\mathbf{0 . 0 2 0} * *$ & $0.760^{\wedge \wedge}$ & $0.232^{\wedge \wedge}$ \\
\hline General health & $1.0(14.0)$ & $0.842 * *$ & $-0.3(15.4)$ & $0.907 * *$ & $0.682^{\wedge \wedge}$ & $0.885^{\wedge} \wedge$ \\
\hline
\end{tabular}

* The Wilcoxon Signed Ranks Test was used except ** the Paired Samples T Test was used. $\wedge$ The Mann-Whitney’s U Test was used except $\wedge^{\wedge} \wedge$ the Independent Samples Test was used. 


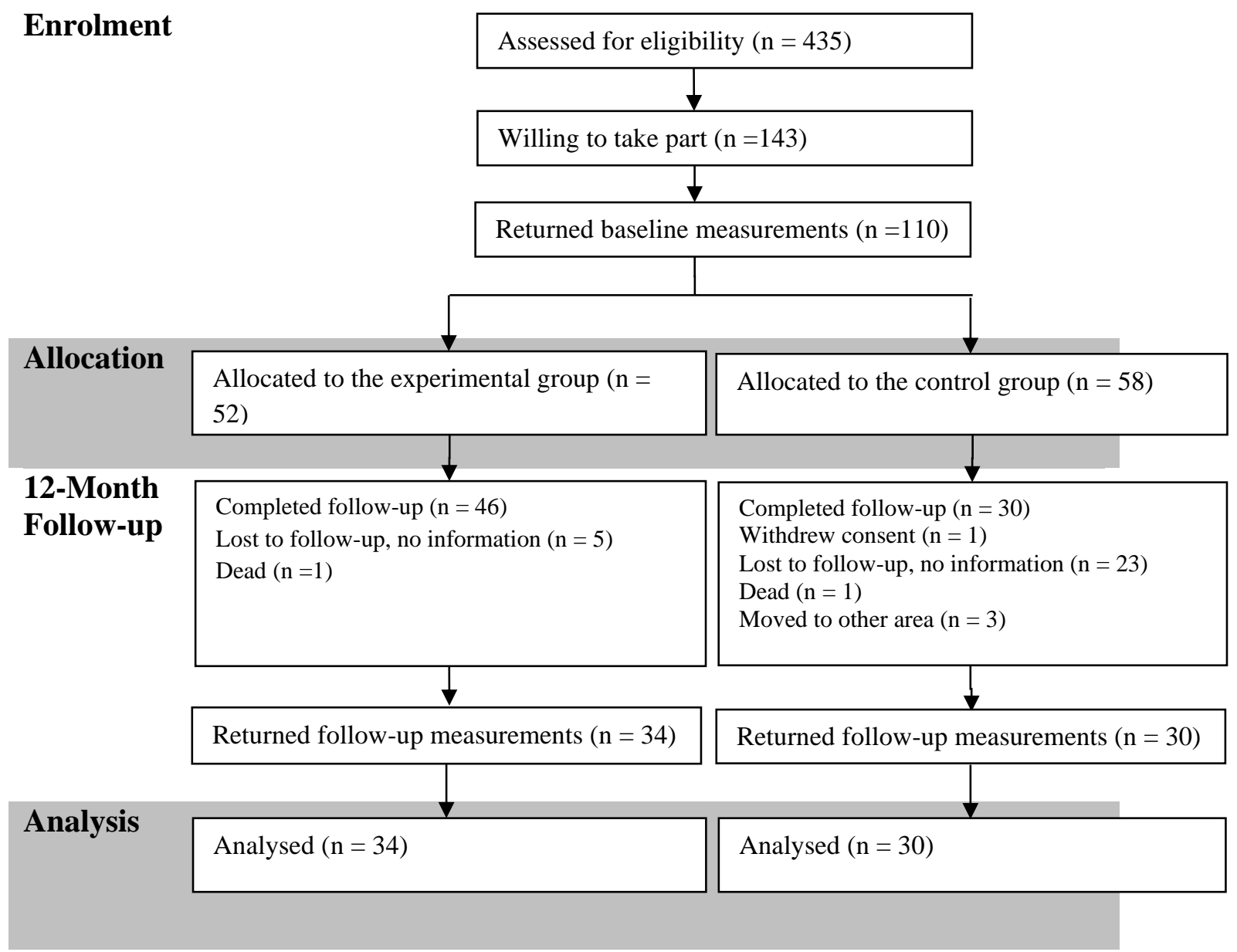

Figure 1. Flow diagram of participants through health-coaching study. 


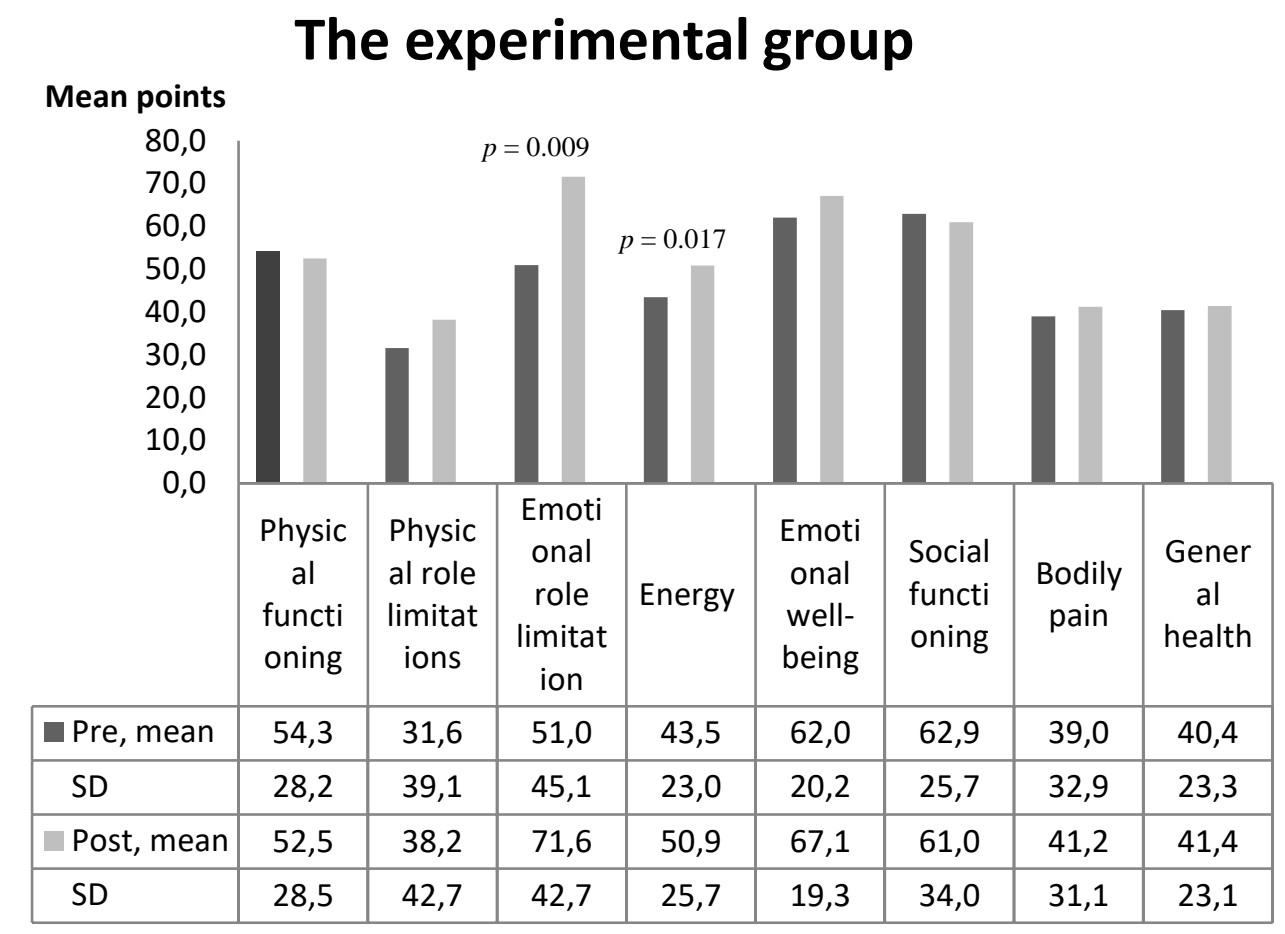

The control group

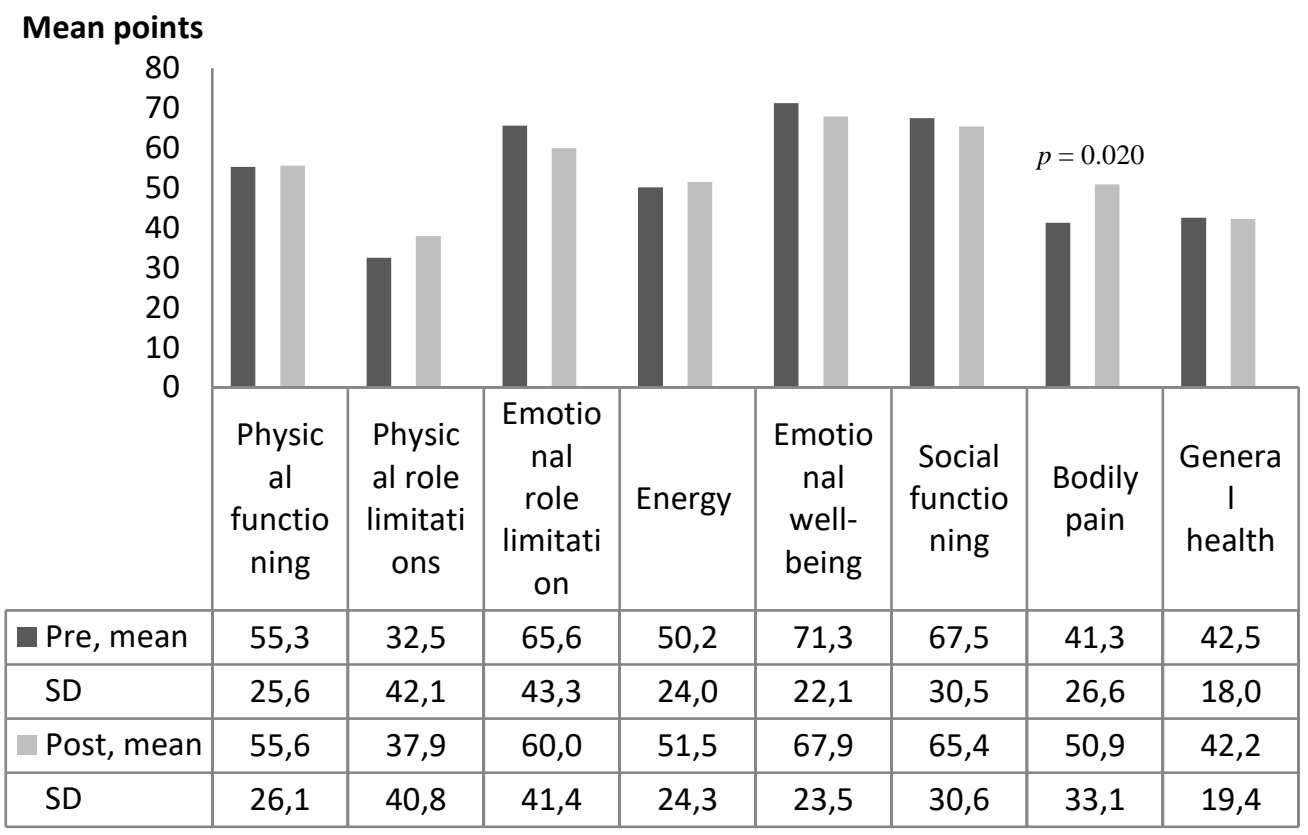

Figure 2. Health-related quality of life for eight scales of measurements at baseline (pre) and after 12 months (post). 


\begin{tabular}{|c|c|c|c|c|}
\hline \multicolumn{5}{|l|}{160,0} \\
\hline 140,0 & \multirow{4}{*}{$\rho=0.291$} & & & \\
\hline 120,0 & & & & \\
\hline 100,0 & & & & \\
\hline 80,0 & & & & \\
\hline 60,0 & & & & \\
\hline 40,0 & & & & \\
\hline 20,0 & & & & \\
\hline 0,0 & Weight (kg) & BMI $\left(\mathrm{kg} / \mathrm{m}^{2}\right)$ & $\begin{array}{l}\text { Systolic blood } \\
\text { pressure } \\
(\mathrm{mmHg})\end{array}$ & $\begin{array}{c}\text { Diastolic blood } \\
\text { pressure } \\
(\mathrm{mmHg})\end{array}$ \\
\hline Pre, mean & 72,9 & 26,4 & 141,1 & 79,7 \\
\hline SD & 16,0 & 5,5 & 17,3 & 8,6 \\
\hline Post, mean & 73,2 & 26,3 & 136,8 & 75,8 \\
\hline SD & 16,4 & 5,6 & 20,4 & 11,3 \\
\hline Post-pre changes, mean & 0,3 & 0,0 & $-4,3$ & $-3,8$ \\
\hline SD & 3,5 & 1,3 & 17,6 & 9,6 \\
\hline
\end{tabular}

P values was used by the Wilcoxon Signed Ranks Test except $\rho$ value* was used by the Paired Samples T Test.

Figure 3. Clinical health outcomes of the experimental group $(\mathrm{n}=34)$. 